\title{
Comparison of Electrocoagulation and Chemical Coagulation Processes in the Treatment of an Effluent of a Textile Factory
}

\author{
*1TCHAMANGO, SR; ${ }^{2}$ KAMDOUM, O; ${ }^{2}$ DONFACK, D; ${ }^{2}$ BABALE, D \\ ${ }^{1}$ University of N'Gaoundéré, Faculty of Science, Department of Chemistry, P.O. Box 454, N'Gaoundere-Cameroon \\ ${ }^{2}$ University of Yaoundé I, Faculty of Science, Department of inorganic Chemistry, \\ Laboratory of Analytical Chemistry P.O. Box 812 Yaoundé-Cameroon \\ *E-mail address:tchamangos@yahoo.fr ( Tchamango S.R)
}

\begin{abstract}
In this work, electrocoagulation and chemical coagulation were applied to the exit effluent of a textile factory located at Douala (Cameroon).The investigations were focused on the operational ( $\mathrm{pH}$, conductivity) and pollution parameters (COD, total phosphorus, turbidity). The electrolytic treatment was carried out with $0.4 \mathrm{~A}$ current intensity, and chemical coagulation was conducted in adding initially to the effluent the same quantities of aluminium than that electrogenerated.the elimination of pollution contents depended on the quantity of $\mathrm{Al}^{3+}$ ions produced by the electrodissolution of the aluminium anode and that of the aluminium salt dissolved in solution. In fact, 58.86, 94.44 and $97.81 \%$ of COD, total phosphorous and turbidity were respectively removed by electrocoagulation, while hemical coagulation, the turbidity was also reduced roughly at the same level as by electrolytic treatment. Also, 56.08 and $63.64 \%$ COD and total phosphorus were respectively removed by chemical route. During electrocoagulation, highest removals were reached after $2.49 \times 10^{-3} \mathrm{~mol}$ of aluminum was released in solution (after 30 minutes of treatment). Thus, the final $\mathrm{pH}$ obtained by this process was around 9 and the conductivity varying slightly, compared to the initial value. By contrast, chemical coagulation rendered the effluent more acidic and more conducting $\left(\gamma>4 \mathrm{mS} . \mathrm{cm}^{-1}\right)$. Electrocoagulation is the best process, by the fact that the textile effluent treated by this technique can be re-used or rejected without risk in the environment. Chemical coagulation: indeed, the corrosive nature of effluent treated by this method and the significant content of the residual phosphorus can seriously inhibit the perspective of recycling.
\end{abstract}

Copyright @ 2017 Tchamango et al. this is an open access article distributed under the Creative Commons Attribution Non-Commercial License (CC-BY-NC), which permits unrestricted use, distribution, and reproduction in any medium, provided the original work is properly cited.

DOI: https://dx.doi.org/10.4314/jasem.v21i7.17

Received 23 July 2017, received in revised form 09 September 2017, accepted 2 December 2017.

Keywords: Electrocoagulation, Chemical coagulation, Textile effluents, Removal efficiency

The textile industry consumes large amounts of water in the dyeing and finishing processes. Generally, the produced effluents are characterised by strong colour, low metal and suspended particles contents, high temperature, alkaline $\mathrm{pH}$, low biodegrability in most cases, high chemical oxygen demand (COD), (Mollah et al., 2004; Rodrigues et al., 2009,). World production of textile dyes is estimated as $7 \times 10^{5}$ tons per year (Davland et al., 2011; Khandegar et al., 2013).

Due to the toxicity of the textile effluents, the textile industry faces to environmental and social challenges. In fact, about $15 \%$ of dyes are released in textile effluents, due to their limited fixation efficiency (Vatanpour et al., 2009). The textile dyeing units consume large quantities of water at different steps of dyeing and finishing among other processes. Almost $10-50 \%$ of all used reactive dyes after dyeing of textile goods such as cotton, wool, and polyamide remain in effluent (Sadeghi-Kiakhani et al., 2013). In developing countries, these effluents are directly discharged into rivers or any other natural water streams causing serious pollution problems and endangering persons and aquatic life (Mollah et al., 2004). Besides political regulations imposed, it is also necessary to find effective wastewater treatments capable of removing colour and degrading toxic organic compounds from textile effluents. The conventional methods to treat the textile effluents are composed of various combinations of the biological, chemical and physical methods, varying in performance, cost-effective, and ecofriendly aspects (Kobya et al., 2003; Bayramoglu et al., 2004).

Electrocoagulation provides a simple, reliable and cost-effective method for the treatment of effluents without any need of additional chemicals. It also reduces the amount of sludge, which needs to be disposed (Daneshvar et al., 2006).

Electrocoagulation presents many advantages compared to conventional methods, such as high removal efficiencies at low capital and operation costs, simplicity and compactness of the equipment required and easiness to control the process, leading to the robustness. Thus by this process, the need for additional chemicals and the sludge production is reduced significantly, compared to chemical coagulation (Mollah et al., 2001; Chen, 2004).Many investigations on the electrocoagulation of the textile effluents has been carried out,

The objective of this work is to compare the efficacy of electrocoagulation and chemical coagulation processes during the treatment of textile effluent. The investigations are focused on the influence of the $\mathrm{Al}^{3+}$ ions on the removal of some pollution parameters (turbidity, total phosphorus and COD). 


\section{MATERIALS AND METHODS}

The effluent which is the subject of this study was sampled in the decantation tank of a textile factory in Douala (Cameroon). Cubic meters of textile effluent were stored in this tank, where converges all ultimate waters coming from all the operations of the factory before their rejection.

The $\mathrm{pH}$ and conductivity measurements were achieved with a Multi340i/SET of Weight Watchers International (WTW). These devices were connected to electrodes comprising a temperature sensor. The $\mathrm{pH}$ was adjusted if necessary by adding $10^{-1} \mathrm{M} \mathrm{H}_{2} \mathrm{SO}_{4}$ (98\%, from Riedel de Haën), or $\mathrm{NaOH}$ (from Prolabo) at the same concentration. A Stuart magnetic stirrer was used in order to get a good homogenisation of the textile effluent sample during the treatment.

The current was provided by an ERMES M10-SP-303, 3A-30V DC power supply. The Chemical Oxygen Demand (COD) and the total phosphorus were analysed with a HACH DR 2500 Odyssey spectrophotometer. In the case of the COD measurement, the sample to be analysed was first heated in a HACH thermostat, type DRB 200.

The turbidity was measured using a Lovibond turbidimeter. The experiments were performed in $100 \mathrm{~mL}$ beaker, acting as reactor. A pair of aluminium procured in the local market, and connected to a DC power supply was used as electrodes. Their dimensions were $10 \mathrm{~cm} \times 4 \mathrm{~cm} \times 0.5 \mathrm{~cm}$, and these electrodes were separated by a polyethylene grid of 0.5 $\mathrm{cm}$ thickness and immersed in the solution to treat at a $5 \mathrm{~cm}$ height. The imposed current was $0.4 \mathrm{~A}$, and the electrocoagulation processing time was varied from 0 to 40 minutes. The electrodes were weighed before and after the runs, in order to evaluate the current efficiency, according to the relation: $\eta(\%)=\frac{\text { Experimental mass }}{\text { Theoretical mass }} \times 100$

With an aim of establishing a comparison with the electrocoagulation, aluminium sulphate $\mathrm{Al}_{2}\left(\mathrm{SO}_{4}\right)_{3} .14$ $\mathrm{H}_{2} \mathrm{O}$ (Prolabo) was used during chemical coagulation experiments.

For this to be achieved, aluminium sulphate corresponding to the same quantities as that of electrogenerated (by electrocoagulation) was weighed and added to the textile effluent. After this stage, the whole was stirred during approximately 10 minutes and analysed.

\section{RESULTS AND DISCUSSION}

Preliminary study of the textile effluent: Before beginning the treatment by both processes (chemical coagulation and electrocoagulation), the $\mathrm{pH}$ of the exit effluent in the decantation tank was measured (it is the effluent which is directly rejected into nature).his $\mathrm{pH}$ was higher than 14 because of enormous quantity of soda used in the manufacturing process of textile. For this reason, chemical and electrochemical treatments were not possible.

When the medium is strongly alkaline, aluminate ion $\mathrm{Al}(\mathrm{OH})_{4}^{-}$is formed, thus inhibiting the treatment (soluble species soluble which does not contribute to the flocks formation) (Chen, 2004; Tchamango et al., 2010).

To solve this problem, we added to the samples before each run, sulphuric acid to lower the $\mathrm{pH}$ to a value where coagulation is possible. Diagram 1 illustrates the procedure of the textile effluent treatment we followed

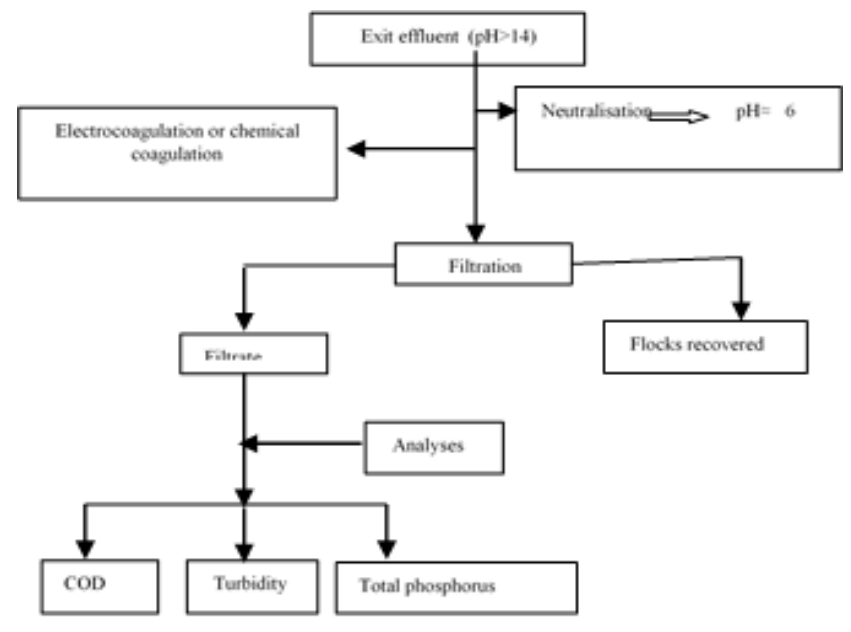

Fig 1. Illustration of the treatment procedure 
Table 1: Characteristics of the textile effluent before the treatment. After neutralisation, the values of operational and pollution parameters

\begin{tabular}{lcccccc}
\multicolumn{7}{c}{ were recorded, as shown in table 1. } \\
\hline Physicochemical and pollution parameters & $\gamma\left(\mathrm{mS}^{\left.-\mathrm{cm}^{-1}\right)}\right.$ & $\mathrm{pH}$ & $\begin{array}{c}\text { COD } \\
\left(\mathrm{mg} . \mathrm{L}^{-1}\right)\end{array}$ & $\begin{array}{c}\text { Turbidity } \\
(\mathrm{FNU})\end{array}$ & $\begin{array}{c}\text { Total phosphorus } \\
\left(\mathrm{mg} . \mathrm{L}^{-1}\right)\end{array}$ \\
\hline Value & 2.87 & 6.23 & 649 & 64 & 42.24 \\
\hline
\end{tabular}

After reading of this table, we noted that: (i) the values of the COD, total phosphorus and turbidity were above the environmental standards for water of rejection (1996). (ii) The value of the initial conductivity of the effluent was sufficient to favour an electrolytic treatment (iii). The initial $\mathrm{pH}$ of the effluent was now fixed to 6 , value in the range where aluminium hydroxides, necessary for the trapping of the colloidal particles is formed.for the forthcoming experiments, this value was considered.

After having adjusted the $\mathrm{pH}$ and proceeded to electrocoagulation, a progressive formation of the flocks was observed, of which a part rose up on the surface while another decanted by gravity. The textile effluent solution which was initially blue was completely discoloured at the end of the electrolytic treatment.

According to several authors, electrocoagulation implies three successive stages (Mollah et al., 2001): 1. Formation of coagulants by electrolytic oxidation of the sacrificial electrode; 2 . Destabilisation of colloidal particles and breaking of emulsions; 3 . Aggregation of destabilised particles to form flocks.

When aluminium is used as electrode material during electrocoagulation, the treatment is described by equations (2)-(5). At the electrodes (anode and cathode), electro-dissolution of aluminium and water reduction occur respectively.

$$
\begin{aligned}
& A l \rightarrow A l^{3+}(a q)+3 e \\
& 3 \mathrm{H}_{2} \mathrm{O}+3 e \rightarrow 3 O \mathrm{H}^{-}+\frac{3}{2} \mathrm{H}_{2}
\end{aligned}
$$

Then $\mathrm{Al}^{3+}$ and $\mathrm{OH}^{-}$electrogenerated react to form many monomeric species $\mathrm{Al}(\mathrm{OH})^{2+}, \quad \mathrm{Al}(\mathrm{OH})_{2}{ }^{+}$ $\mathrm{Al}_{2}(\mathrm{OH})_{2}{ }^{4+} \mathrm{Al}(\mathrm{OH})_{4}{ }^{-}$andpolymeric species such as $\mathrm{Al}_{6}(\mathrm{OH})_{15^{3+}}, \mathrm{Al}_{7}(\mathrm{OH})_{17^{4+}}, \mathrm{Al}_{8}(\mathrm{OH})_{20}{ }^{4+}, \mathrm{Al}_{13}(\mathrm{OH})_{34^{5+}}$, and $\mathrm{Al}_{13} \mathrm{O}_{4}(\mathrm{OH})_{24}{ }^{7+}$ which transform finally into $\mathrm{Al}(\mathrm{OH})_{3}$ by complex precipitation kinetics (Alansafi $e t$ al., 2005; Yilmaz et al., 2007) :

$$
A l^{3+}(a q)+3 \mathrm{H}_{2} \mathrm{O} \rightarrow \mathrm{Al}(\mathrm{OH})_{3}+3 \mathrm{H}^{+}
$$

The produced $\mathrm{Al}(\mathrm{OH})_{3}$ flocks remain as a suspension and can effectively capture the dye molecules present in the textile effluent by the following reaction mechanism (Davland et al., 2011) :

$$
D Y E-H+(\mathrm{OH}) O A l_{(s)} \rightarrow D Y E-O A l_{(s)}+\mathrm{H}_{2} \mathrm{O}
$$

At high $\mathrm{pH}$ values, cathode and anode may be attacked by $\mathrm{OH}^{-}$by corrosion, also leading to the formation of aluminate ion (Picard et al., 2000):

$2 \mathrm{Al}+6 \mathrm{H}_{2} \mathrm{O}+2 \mathrm{OH}^{-} \rightarrow 2 \mathrm{Al}(\mathrm{OH})_{4}^{-}+3 \mathrm{H}_{2}$

During the treatment, the hydrogen micro bubbles which are released at the cathode displace the flocks formed during electrolysis in their upward movement on the surface of the solution by electro flotation (Tchamango et al., 2010).

The electrode consumption is a proof that electrocoagulation occurs, and the decrease of the electrode mass is observed according to the Faraday's law:

$\mathrm{m}_{\mathrm{th}}=\frac{\mathrm{I} \cdot \mathrm{t} \cdot \mathrm{M}}{\mathrm{z} \cdot \mathrm{F}}$

In this relation, $\mathrm{m}_{\mathrm{Th}}$ is the theoretical consumed metal mass, I is the current intensity imposed (A), $t$ is electrocoagulation time (s), $\mathrm{M}$ is the molar mass of electrogenerated metal $\left(\mathrm{g} \cdot \mathrm{mol}^{-1}\right), \mathrm{z}$ is the number of electrons released by the anode oxidation $(z=3$ for aluminium) and $\mathrm{F}$ is Faraday's constant $\left(96,486 \mathrm{C} \mathrm{mol}^{-}\right.$ 1) (Chen et al., 2000; Adhoum et al., 2004). After each experiment, the electrodes were regularly cleaned with deionised water, dried in an oven for about two minutes and weighed.

We studied the impact of the corrosion on aluminium anode by evaluating the current efficiency, relationship expressed as a percentage between the theoretical aluminium mass (calculated according to the Faraday's law) on its experimental one (obtained by weighing anode).

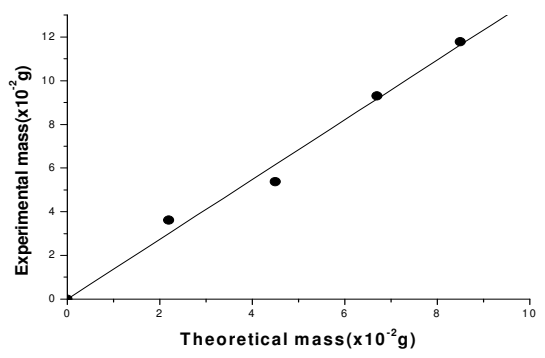

Fig 2: Variation of the experimental mass against the theoretical mass of aluminium during the treatment of textile effluent. Electrocoagulation time $=40$ minutes.

On this figure, the value 100xslope represents the current efficiency. The value obtained (approximately 136\%) indicates the extent of the corrosion that occurred. Indeed, during electrocoagulation with aluminium electrodes the 
current efficiency is always higher than $100 \%$, because of chemical corrosion mainly due by chloride ions (Chen et al., 2000; Tchamango et al., 2016). In this case, it is obvious that the strong alkalinity of the effluent, due to the soda which intervenes in the manufacturing process of the textile also contributes to increase this corrosion, and consequently the current efficiency. The last explanation of the current efficiency value is "Chunk effect" phenomena: actually during electrolyses, quantities of aluminium are unhooked from the electrodes, under the influence of the current, and thus increase their experimental masses (Dineff and Sabeva, 2004).

Study of the physicochemical parameters; Study of the $\mathrm{pH}$ variation: The $\mathrm{pH}$ of the effluent is a very important factor during electrocoagulation and chemical coagulation. Indeed, this parameter conditions the formation of the metal hydroxides which these processes need to eliminate the pollutants (Chen et al., 2000). During chemical coagulation, the $\mathrm{pH}$ must be as a preliminary initially in the zone where constitution of the flocks is favoured (Degremont, 2005). But, electrocoagulation led with the aluminium electrodes requires only that initially the $\mathrm{pH}$ is acidic or neutral. In alkaline medium, the electrolytic treatment is inhibited by the formation of aluminate ion, as mentioned early.

Fig. 2 depicts the variation of the $\mathrm{pH}$ against the number of mol of aluminium during the treatment of the textile effluent by both processes.ne firstly notices on this figure that the $\mathrm{pH}$ increases during electrocoagulation, and this is dueto the formation of hydroxyl ions at the cathode according to equation (3).as soon as the aluminium hydroxide is sufficiently formed, it reacts with the excess of hydroxyl ions released at the cathode during water reduction and lowered the $\mathrm{pH}$, according to the equation below (Chen et al., 2000):

$\mathrm{Al}(\mathrm{OH})_{3}+\mathrm{OH}^{-} \rightarrow \mathrm{Al}(\mathrm{OH})_{4}^{-}$

By contrast chemical coagulation induces a $\mathrm{pH}$ drop; the more the quantity of aluminium sulphate is added to the effluent, the more the decrease of the $\mathrm{pH}$ is observed: the $\mathrm{Al}^{3+}$ hydrolysis releases the protons which by their strong acidity lower this parameter in equation 4 .

Study of the conductivity variation: We studied the influence of the conductivity in this work for several reasons:(i) an electrolytic treatment requires a sufficiently conducting medium, so that the imposed current not mainly serf to heat the solution of textile effluent and increase the energy consumption by Joule effect(ii). Considering the enormous quantity of water used by textile industries, very conducting water produced by a process would limit its effectiveness from the point of view of recycling of this water (Tchamango et al., 2016).

In Fig. 3 is represented the evolution of conductivity against the number of mol of aluminium. The conductivity decreases during electrocoagulation, but increases when the aluminium sulphate in added in the effluent. The drop of the conductivity can be explained by the trapping of certain conducting species contained in the effluent, particularly the protons, following the production of hydroxyl ions at the cathode (Eq. 2).
By contrast, in the case of chemical coagulation, the $\mathrm{Al}^{3+}$ hydrolysis produces protons, which increase the conductivity of the effluent (Eq. 4). Sulphate ions formed during the dissolution of aluminium salt and which do not intervene in the process of coagulation also contribute to increase this parameter (Tchamango, 2010).

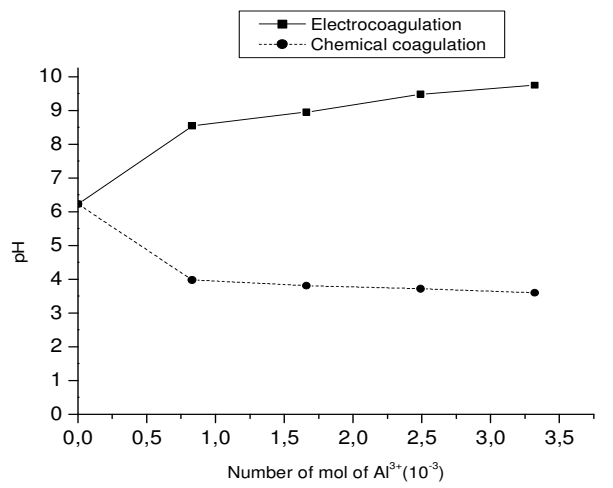

Fig 3: Variation of the $\mathrm{pH}$ during electrocoagulation and chemical coagulation of the textile effluent.

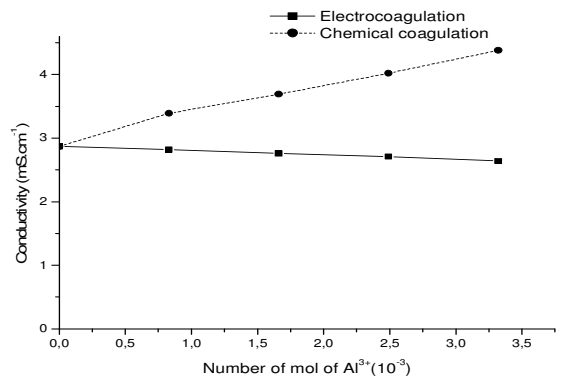

Fig 4: Variation of the conductivity during electrocoagulation and chemical coagulation of the textile effluent.

Study of the pollution parameters: Figs. 4, 5 and 6 describe the effect of respectively the number of mol of aluminium on the turbidity, COD and the total phosphorus elimination during electrocoagulation and chemical coagulation. From the start, one notices on all these figures that a significant proportion of these parameters are eliminated when only $0.83 \times 10^{-3} \mathrm{~mol}$ of aluminium ions is formed (that corresponds to 10 minutes of electrocoagulation treatment). The removal efficiency of the turbidity against the number of mol of aluminium ions is shown in Fig. 4. It is observed on this figure that the production of $0.83 \times 10^{-3} \mathrm{~mol}$ of aluminium in solution (chemically or electrochemically) eliminates up to 97.34 and $98.17 \%$ of the turbidity, respectively by electrocoagulation and chemical coagulation. After this stage, the turbidity varies very slightly until the end of the treatment. These high removals are not surprising; in fact when one analyses the $\mathrm{pH}$ variation curves (Fig. 2), one notice that for this quantity of aluminium produced, the formation of the aluminium hydroxide is significant. On the other hand aluminate ion prevails when the quantity of aluminium exceeds $0.83 \times 10^{-3} \mathrm{~mol}$, which justifies the weak variation of the turbidity. 


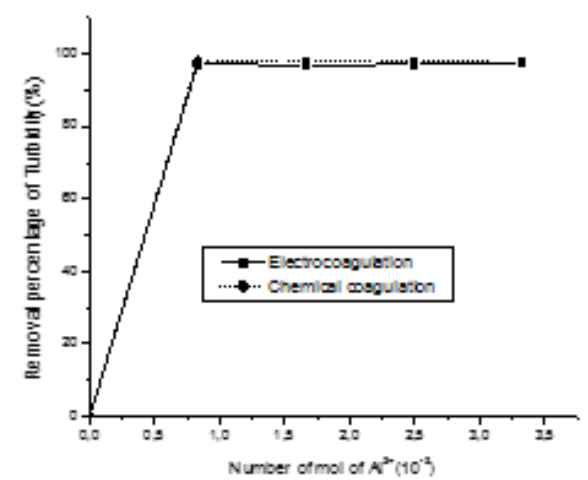

Fig 5: Effect of the quantity of $\mathrm{Al}^{3+}$ on the turbidity removal during electrocoagulation and chemical coagulation of the textile effluent.

As depicted in Fig. 5, one also observes a significant elimination of total phosphorus during electrocoagulation when $0.83 \times 10^{-3} \mathrm{~mol}$ of aluminium is produced, leading to 93.13\% removal. It is not the case for chemical coagulation, where only $19.89 \%$ of total phosphorus is eliminated for the same quantity of aluminium generated. The total phosphorus contents are then stabilised during electrocoagulation, while the removal percentage of this parameter continuously increases during chemical coagulation. At the end of the treatment, respectively 94.44 and $56.08 \%$ of this parameter are eliminated by electrochemical and chemical processes. The difference between the two results could be explained by the presence of orthophosphates in the effluent. Tchamango et al., (2010) have showed that during the electrocoagulation of orthophosphoric acid solution, the phosphates in this case are not trapped by the aluminium hydroxide, but eliminated by electrochemical precipitation. That finding was confirmed by Flilissa et al., (2016)] when studying the variation of $\mathrm{pH}$ during the phosphate-assisted electrocoagulation. This mode of elimination is not possible with chemical coagulation, because of the lack of electrochemical reactions in this process.

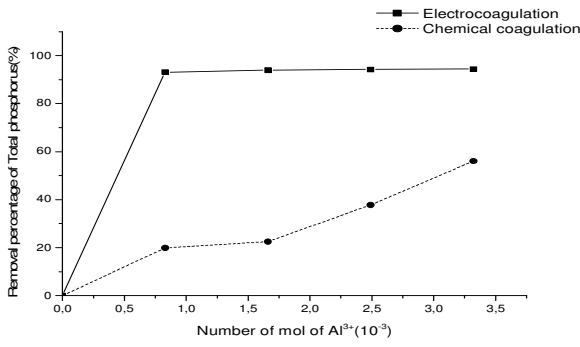

Fig 6: Effect of the quantity of $\mathrm{Al}^{3+}$ on the total phosphorus removal during electrocoagulation and chemical coagulation of the textile effluent.

As quoted in Fig. 6, the evolution of the COD removal is similar by both processes, with the difference that its elimination is more important when aluminium salt is used. Moreover as observed in the case of turbidity and total phosphorus, a great proportion of COD is eliminated at the beginning of the treatment. That is confirmed by the strong slopes on the curves between 0 and $0.83 \times 10^{-3} \mathrm{~mol}$, leading to 48.23 and $54.55 \%$ removal efficiencies by electrocoagulation and chemical coagulation respectively. After this step, the COD removal variation is weak. When the quantity of aluminium ions in the solution is $3.32 \times 10^{-3}$ $\mathrm{mol}$ (end of the treatment), we notice that 58.86 and $63.64 \%$ of the COD are respectively eliminated by electrocoagulation and chemical coagulation.

The analysis of these curves also shows that the elimination of the COD is partial, and that a good proportion of this parameter remains in the effluent after treatment. This situation can be explained by the fact that there also exists in the textile effluent miscible and soluble organic compounds, which do not react with aluminium hydroxide and remain in solution (Moreno-Casillas et al., 2007).

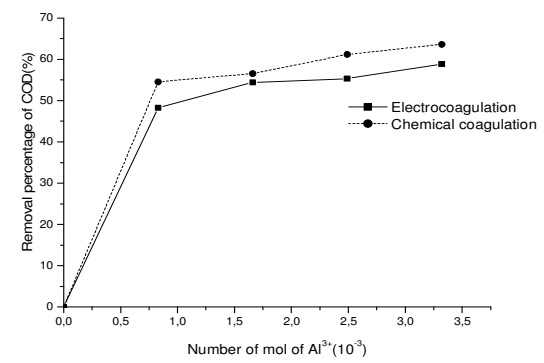

Fig 7: Effect of the quantity of $\mathrm{Al}^{3+}$ on the COD removal during electrocoagulation and chemical coagulation of the textile effluent

When we compare both processes, we notice that: (i) electrocoagulation is more effective to eliminate total phosphorus and thus presents a very high removal of this parameter compared to chemical coagulation $(94.44 \%$ against $56.08 \%$ ). The effluent resulting from chemical coagulation can induce eutrophication of the rivers, because of residual phosphorus contrary to the electrocoagulation which has a harmlessness on the environmental level.The removal of the COD is better with chemical coagulation; (ii) the elimination of turbidity by both processes is almost identical.

If we make a study of the reagents consumption (aluminium anode and aluminium sulphate), it would be interesting to exploit the experimental mass of electrogenerated aluminium and of aluminium sulphate dissolved in the textile effluent. For example after 40 minutes of electrolytic treatment (what corresponds to $3.32 \times 10^{-3} \mathrm{~mol}$ ) the experimental mass of consumed aluminium during electrolyses is $0.122 \mathrm{~g}$, which is equivalent to $2.684 \mathrm{~g}$ of aluminium sulphate. Thus chemical coagulation uses approximately 22 times of reagent, compared to electrocoagulation. The $\mathrm{pH}$ and conductivity measurements clearly show that the effluent treated by chemical coagulation is more acidic and corrosive, and consequently cannot be recycled. By integrating the secondary pollution, the quantity of the reagents used the perspective of recycling the treated effluent and effectiveness of the treatment aspects; electrocoagulation is more advantageous than chemical coagulation.Conclusion: In this study, the influence of $\mathrm{Al}^{3+}$ ions on the treatment of a textile effluent by electrocoagulation and chemical coagulation processes was examined. The results showed that the elimination of the pollution parameters is strongly dependent on the quantity of electrogenerated metal, or of aluminium salt dissolved. Electrocoagulation seems to be the recommended technique, owing the fact that it is less expensive, does not induce secondary pollution and produces treated effluent which can be then recycled.Chemical coagulation on the other hand generated a treated effluent corrosive and more acidic.Moreover, the elimination of phosphorus by this technique is not significant, and can induce eutrophication of waters.The authors thank the French Ministry of the Foreign 
Affairs (AIRES-Sud $\mathrm{N}^{\circ} 7134$ Programme) and the World Academy of Science (TWAS Research Unit) for financing the project $\mathrm{N}^{\circ} 07-052-\mathrm{LDC} / \mathrm{CHE} / \mathrm{AF} / \mathrm{AC}$.

\section{REFERENCES}

Adhoum, N; Monser, L; Bellakhal, N; Belgaied, J-E (2004). Treatment of ectroplating wastewater containing $\mathrm{Cu}^{2+}, \mathrm{Zn}^{2+}$ and $\mathrm{Cr}(\mathrm{VI})$ by electrocoagulation, J. Hazard. Mater.112: 207-213.

Alinsafi, A; Khemis, M; Pons, MN.; Leclerc, JP; Yaacoubi, A; Benhammou, A; Nejmeddine, A (2005). Electrocoagulation of reactive textile dyes and textile wastewater, Chem. Eng. Proc. 44: 461-470.

Bayramoglu, M; Kobya, M; Can, OT; Sobzir, M (2004) .Operating cost analysis of electrocoagulation of textile dye wastewater, Sep. Purif. Technol. 37: 117-125.

Bayramoglu, M;Eyraz, .; Kobya, M (2007). Treatment of textile wastewater by electrocoagulation: economical evaluation, Chem. Eng. J. 128: 155-161.

Can, OT; Kobya, M; Dermibas, E; Bayramoglu, M (2006). Treatment of the textile wastewater by combined electrocoagulation, Chemosphere. 62: 181-187.

Chen, G (2004). Electrochemical technologies in wastewater treatment, Sep. Purif. Technol. 38: 11-41.

Chen, X; Chen, G;Yue, PL. (2000).Separation of pollutants from restaurant wastewater by electrocoagulation, Sep. Purif. Technol.19: 65-76.

Daneshvar, N; Aladegaragoze, A; Djafarzadeh, N (2006).Decolorization of basic dye solutions by electrocoagulation: An investigation of the effect of operational parameters, J. Hazard. Mater. B129: 116122.

Davland, A; Gholami, M; Joneidi, A; Mahmodi, NM (2011).Dye removal, energy consumption and operating cost of electrocoagulation of textile wastewaters as a clean process, Clean-Soil, Air, Water. 39 (7): 665-672.

Décret Loi $N^{\circ}$ 96/12 du 5 août 1996, Loi cadre Camerounaise relative à la gestion de l'environnement. 1996.

Degremont.(2005). Mémento technique de l'eau $10^{\text {th }}$ Edition, Techniques et Documentation.

Dineff, PD and Sabeva, EK (2004). Effect of some electric factors of the effective oxidation, Indian J. Chem. Technol. 2: 486-494.

Flilissa, A; Méléard, P; Darchen, A (2016). Cetylpyridinium removal using phosphate-assisted electrocoagulation, electroreduction and adsorption on electrogenerated sorbents, Chem. Eng. J. 284: 823-830.
Khandegar, V; Saroha, AK (2013). Electrocoagulation for the treatment of textile industry effluent, A review, $\mathrm{J}$. Environ. Manage. 128: 949-963.

Mollah, MYA; Schennach, R; Parga, JR; Cocke, DL (2001).Electrocoagulation (EC), Science and applications, J. Hazard.Mater.B34: 29-41.

Kobya, M.; Can, OT; Bayramoglu, M (2003). Treament of textile wastewater by electrocoagulation using iron and aluminium electrodes, J. Hazard.Mater. B100: 163-178.

Mollah, MYA.; Pathak, R; Patil, PK; Vayuvegula, M; Agrawal, TS; Gomes, JAG;Kesmez, M; Cocke, DL (2004). Treatment of orange II azo-dye by electrocoagulation (E C) technique in a continuous flow cell using sacrificial iron electrodes, J. Hazard.Mater. B 109: 165-171.

Moreno-Casillas, HA; Cocke, DL; Gomes, JAG; Morkovsky, P; Parga, JR; Peterson, E (2007).Electrocoagulation mechanism for COD removal, Sep. Purif. Technol. 56: 204-211.

Moussa, DT; El-Naas, MH; Nasser, M; Al-Marri, MJA (2017). Comprehensive review of electrocoagulation for water treatment: Potentials and challenges, J. Environ. Manage. 186:24-41.

Picard, T; Cathalifaud-Feuillade, G;Mazet, M; Vandensteendam, C (2000).Cathodic dissolution in the electrocoagulation process using aluminium electrodes, J. Environ. Monit. 2:77-80.

Rodrigues, CSD; Madeira, LM; Boaventura, RAR (2009).Treatment of textile effluent by chemical (Fenton's reagent) and biological (sequencing batch reactor) oxidation, J. Hazard.Mater. 172: 1551-1559.

Sadeghi-Kiakhani, M; Arami M; Gharanjig, K (2013). Dye Removal from Colored-Textile Wastewater using Chitosan-PPI dendrimer hybrid as a biopolymer: optimization, kinetic, and isotherm studies, J. Appl. Polym. Sci. 127: 2607-2619.

Tchamango, S; Nanseu-Njiki, CP; Hadliev, D; Ngameni, E, Darchen, A (2010).Treatment of dairy effluent by electrocoagulation using aluminium electrodes, Sci. Total Environ. 408: 497-502.

Tchamango, S; Kamdoum, O; Donfack, D; Babale, D; Ngameni, E (2016).Comparison of electrocoagulation and chemical coagulation in the treatment of artisanal tannery, Nijotech. 35: 219-225.

Vatanpour, V; Daneshavar, N; Rasoulifard, MH (2009) Electrofenton degradation of synthetic dye mixture: influence of intermediates, J. Environ. Eng. Manage. 19(5): 277-282.

Yilmaz, AE; Boncukcuoglu, R; Kocakerim, M; Keskinler, B (2007).The investigation of parameters affecting boron removal by electrocoagulation method, J. Hazard.Mater.144: 101-107 